\title{
Sea water desalination using square wave powered by solar energy
}

\author{
Sherif A. Kamal \\ Building and Construction Department, Faculty of Engineering, October 6 University \\ Cairo
}

Received: $30-01-2014$

Accepted: 20-02-2014

Published:01-03-2014

*Corresponding author: email: dr.eng.sherif@gmail.com T: :+2-(010)00001313

\begin{abstract}
Growth of population, increasing urbanization and industrialization, and the rather limited natural resources of potable water leading to serious deficits of freshwater in many regions in the world specially in middle east and golf area. Current water desalination techniques are energy intensive leading to inhibit the wide use of current sea desalination techniques. In this research a lab scale pilot was introduced using a special electrolysis circuit and vibrator producing a square wave powered by solar energy to decrease $35 \%$ of the total dissolved salts/hour in sea water samples.
\end{abstract}

Key Words: Desalination, Electrolysis, Electrodialysis, Solar energy and Renewable energy.

\section{Introduction}

Water shortage is one of the most important limitations of life, agriculture and industries. Most of the earth surface is covered by water, which is in the form of the oceans, seas and ice in the poles. However, only $1 \%$ of this water, which is in the form of surface or underground water, can be used by human beings without being desalinated (1). The water of the oceans and seas is salty and thus not directly utilizable. Therefore, some special processes are needed to desalinate these waters (2). The TDS of sea water is very high $(35,000-50,000$ ppm) which depends on location, weather, and whether or not there are pollutants from nearby cities, households, and industries. Some examples of sea water content in several places: normal sea water content is $35,000 \mathrm{ppm}, 42,000 \mathrm{ppm}$ in Red Sea, more than 50,000 ppm around Arabic Peninsula (3)
The available salt content reduction process, or desalination, is: by evaporation, distillation, and with membrane process. In desalination with membrane process, there are three methods available: Reverse Osmosis, Membrane Distillation, and Electrodialysis. (4)

\section{Material and method}

The Experiment operation and the device were built in October 6 University, faculty of engineering laboratories and resulted samples was analyzed in Egyptian Environmental Affairs Agency laboratory. The experiment samples were collected from Red sea at Ain sokhna, Egypt. The experiments were conducted in a lab-scale device system. The settling time was $5 \mathrm{~h}$ at $30 \mathrm{Co}$. The bench scale experiment consisted of a stainless steel plates (Sus 316) (W200mm - L300mm) H200 mm), inside which 3 Pairs cathode-anode were arranged in parallel. 
The gap between the stainless plates was $30 \mathrm{~mm}$. The cathode and anode were made of the same size and material. The capacity volume for the batch used system was 12 Liters.

The electrical current applied to the anode/cathode pairs was controlled by foldable solar cell panel the power was (18W 15V).

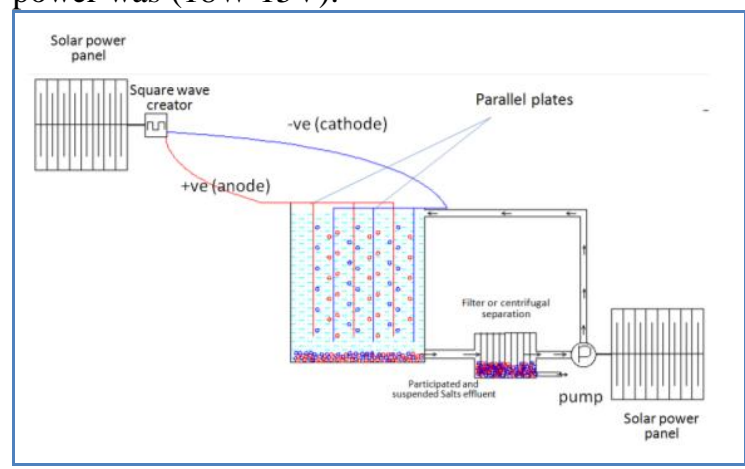

Figure 1. Process scheme with using bench scale devices used.

- Water used in the operation was 4 sea water sample (1 -control sample with salt concentration of $47.89 \mathrm{~g} / \mathrm{l}$ (treated with constant frequency). and 3 samples with concentrations of $49.17 \mathrm{~g} / \mathrm{l}-48.45$ $\mathrm{g} / \mathrm{l}$ - $48.78 \mathrm{~g} / \mathrm{l}$ was desalinated using variable frequency and 20 synthetically salted water was used during the experiment as shown in the following table.

Table 1. Shows the synthetically samples total dissolved concentration.

\begin{tabular}{|c|c|c|c|}
\hline Sampl & Total & Samples & Total \\
\hline 1 & 0.26 & 11 & 11.88 \\
\hline 2 & 1.09 & 12 & 16.03 \\
\hline 3 & 1.92 & 13 & 20.18 \\
\hline 4 & 2.75 & 14 & 24.33 \\
\hline 5 & 3.58 & 15 & 28.48 \\
\hline 6 & 4.41 & 16 & 32.63 \\
\hline 7 & 5.24 & 17 & 36.78 \\
\hline 8 & 6.07 & 18 & 40.93 \\
\hline 9 & 6.9 & 19 & 45.08 \\
\hline 10 & 7.73 & 20 & 49.23 \\
\hline
\end{tabular}

\section{Experimental operation}

The experiments operation begins using wave creator connected to the plates to obtain a square wave with different frequency changes with the salt concentration in the water changes to reach the maximum efficiency as shown in the following table.

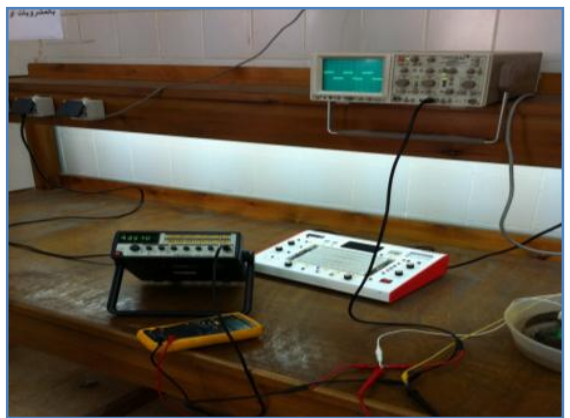

Figure 2. wave creator used

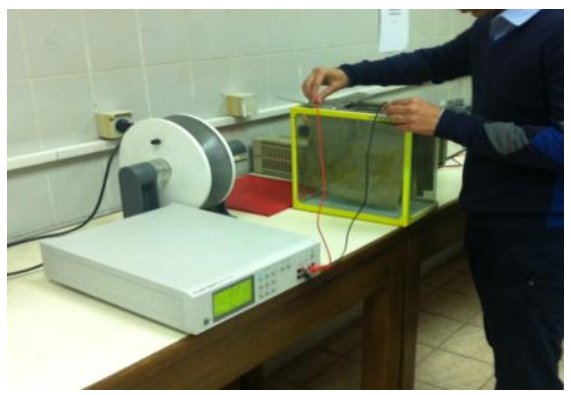

Figure 3. Saltwater resistance and capacitance measure

Table 2. Shows the resistance and capacitance measured for different salt concentration

\begin{tabular}{|c|c|c|c|}
\hline Total & resistance & frequency & capacitance(uF) \\
\hline 0.26 & 4.769 & 1000 & 33.340 \\
\hline 1.09 & 3.407 & 1399.78 & 46.669 \\
\hline 1.92 & 3.029 & 1574.46 & 52.493 \\
\hline 2.75 & 2.985 & 1597.67 & 53.266 \\
\hline 3.58 & 2.896 & 1646.77 & 54.903 \\
\hline 4.41 & 2.74 & 1740.53 & 58.029 \\
\hline 5.24 & 2.724 & 1750.75 & 58.370 \\
\hline 6.07 & 2.707 & 1761.75 & 58.737 \\
\hline 6.9 & 2.702 & 1765.01 & 58.845 \\
\hline 7.73 & 2.694 & 1770.25 & 59.020 \\
\hline 11.88 & 2.685 & 1776.18 & 59.218 \\
\hline 16.03 & 2.673 & 1784.15 & 59.484 \\
\hline 20.18 & 2.661 & 1792.2 & 59.752 \\
\hline 24.33 & 2.649 & 1800.32 & 60.023 \\
\hline 28.48 & 2.64 & 1806.46 & 60.227 \\
\hline 32.63 & 2.631 & 1812.64 & 60.433 \\
\hline 36.78 & 2.619 & 1820.94 & 60.710 \\
\hline 40.93 & 2.598 & 1835.66 & 61.201 \\
\hline 45.08 & 2.587 & 1843.47 & 61.461 \\
\hline 49.23 & 2.576 & 1851.32 & 61.724 \\
\hline
\end{tabular}




\section{Conclusions:}

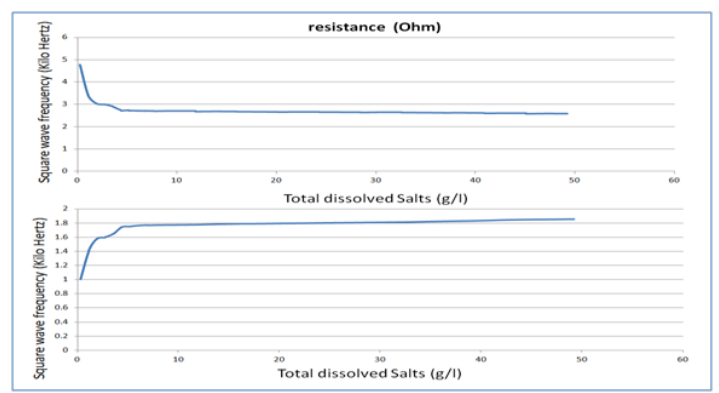

Figure 4. Shows the resistance and capacitance measured for different salt concentration

\section{Results and Discussion}

The figure below shows the result of saltwater desalination of the 4 samples collected from the red sea by operating the device with descending variable frequency according to the salt concentration if compared with control sample using constant wave frequency.

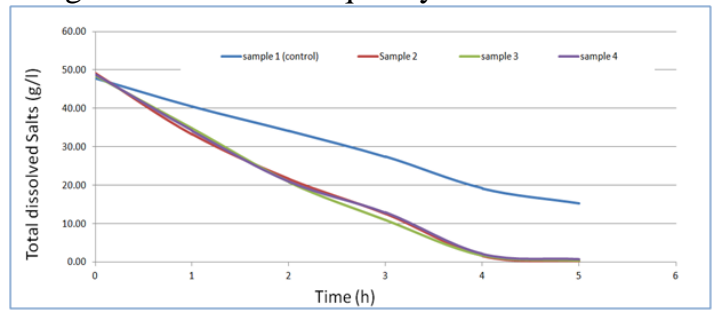

Figure 5. Shows the result of saltwater desalination compared with the control sample

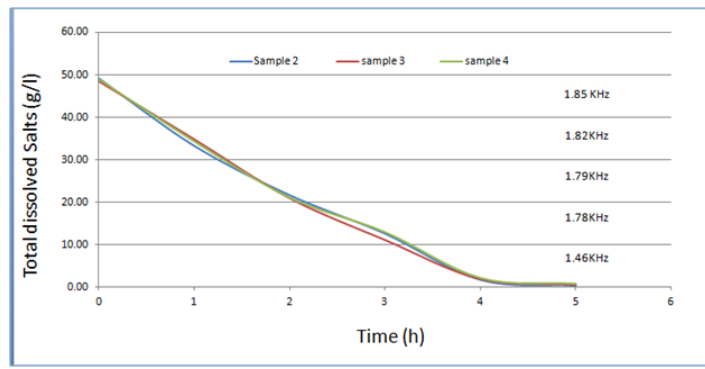

Figure 6. Shows the result of saltwater desalination compared with different frequency value

\section{Conclusion}

Based on the result of this research and data analysis, this research concludes several things as follow:

1-using the square wave with variable frequency have a big effect on the efficiency of the salt water desalination if compared with using constant frequency gives total of $35 \%$ removal after 5 hours.

Also using variable square wave frequency reaches total of $96 \%$ during same 5 hours.

The use of the square wave technology with changing the frequency leaving the volt and watt constant makes using the solar cells in seawater desalination very effective as shown from the research.

\section{References}

1.A.D.Ryabtev, N.P.Kotsupalo, V.I. Titarenko,I. K.Igumenov, N.V.Gelfond, N.E.frdotova, N.B.Morozova,V.A. Shipachev and A.S.Tibilov, Desalination,137(2001)207-214

3. T.Mohammadi and A.Kaviani, water shortage and seawater desalination by electrodialysis, desalination, 155(2003)267-270.

4. Redjeki, S, Reduction of the Energy Usage of Sea Water Desalination with Electrodialysis Process, the 1st International Seminar on Fundamental and Application of Chemical Engineering: ISFAChE 2010, November 3-4, 2010, Bali-Indonesia.

4. A. J. Hartono, M. C. Widiatmoko, Teknologi Mernbram, pemurnian air (Membrane technology for water treatment), Andi Offset, Yogyakarta, 1992. 